\title{
Myocarditis with Hypotension after a Scorpion Sting
}

\author{
Maneesha Erraboina ${ }^{1}$, Bucchi Reddy ${ }^{2}$, Mamatha Reddy ${ }^{3}$, Suresh Bandari ${ }^{1}$ \\ Department of ${ }^{1}$ Pharmacy Practice, Rohini Superspeciality Hospitals and St. Peter's Institute of Pharmaceutical sciences; Department \\ of ${ }^{2}$ General Medicine and ${ }^{3}$ Cardiology, Rohini Superspeciality Hospitals, Warangal, Telangana, India.
}

\section{Corresponding Author:}

Dr. Maneesha Erraboina, Pharm. D

Email: maneesha.pharmd@gmail.com

This is an Open Access article distributed under the terms of the Creative Commons Attribution License (creativecommons.org licenses/by/3.0).

Received Accepted Published

\begin{abstract}
Background: Scorpion stings are common in India and painful but rarely life-threatening. Young children and sometimes the very old are at risk of serious complications. Case Report: A 24 year old female patient was referred with myocarditis after a scorpion sting on left point finger. The patient was treated with noradrenaline, epinephrine, and dopamine infusion. After a week of therapy, patient was discharged following recovery. Conclusion: This case report emphasizes the occurrence of myocarditis after severe scorpion sting.
\end{abstract}

Keywords: Dopamine, Epinephrine, Scorpion Stings, Myocarditis, Norepinephrine.

\section{Introduction}

Most of the scorpion stings are harmless and follow a benign clinical course, but some present with serious and acute life-threatening complication in respiratory, neurologic and cardiovascular systems. Scorpions live in warm dry regions throughout India. In Urban areas, cases of scorpion bite are referred from nearby villages for management of complication arising from scorpion bite [1]. Cardiovascular toxic effects are the most important life-threatening complications of scorpion stings. Immediately following a scorpion sting, an autonomic storm is responsible for hypertension, tachycardia, and shock [2]. Cardiovascular effects are particularly prominent after stings by Indian red scorpion (Mesobuthus tamulus) [3]. In the present study, 24-year-old female patient presented with complaint of a scorpion sting and was determined to have myocarditis with left ventricular dysfunction and hypotension.

\section{Case Report}

A 24 year old female patient presented with a scorpion bite while she was working in farms at her village. Her associated complaints were tachycardia, and hypotension; immediately she was taken to nearby hospital and treated with tablet acetaminophen, injection noradrenaline, and injection dopamine. She came to our emergency department where electrocardiogram (ECG) was taken prior and she was shifted to Intensive Cardiac Care Unit (ICCU) for further treatment. She had a history of one episode of vomiting before hospital admission. The ECG report revealed sinus tachycardia, left anterior hemi-block, antero-septal myocardial infarction; 2D ECHO (echocardiogram) displayed global hypokinesia and severe dysfunction of left ventricle. Chest X-ray was suggestive of right upper lobe consolidation and left mid-zone patchy consolidation. Troponin-T was positive in this patient. Her random blood sugar, electrolytes, serum creatinine and C-reactive protein were normal. Hematological report showed increased neutrophils, while arterial blood gas analysis (ABG) showed decreased partial carbon dioxide $\left(\mathrm{pCO}_{2}\right)$, and bicarbonates and increased partial oxygen $\left(\mathrm{pO}_{2}\right)$.

The complications observed due to scorpion sting in this patient were myocarditis, mild mitral regurgitation, left ventricle dysfunction, 
hypotension, shock, acute kidney injury, bilateral pneumonia. The patient was treated for all complications; recovered and got discharged without any complaints. Before discharge, the patient was counseled about life style changes that includes don't store firewood near the house or inside, wear shoes, gloves and long sleeves and pants while working in farms to avoid scorpion bite.

\section{Discussion}

Scorpion stings are a major public health problem in many tropical countries. Scorpion venom is a water-soluble, antigenic, heterogenous mixture, as demonstrated on electrophoresis studies. This heterogeneity accounts for the variable patient reactions to the scorpion sting [4]. The venom produces both local as well as systemic reactions. Local reactions consist of itching, edema and ecchymosis with burning pain. Absorption of the venom from scorpion - sting site occurs in 7-8 hours. $70 \%$ of maximum concentration of venom in the blood will be reached within 15 minutes and then time needed to reach maximum venom blood concentration is $101 \pm 8$ minutes in experimental animals, half-life of intravenously injected venom is between 4 to 7 minutes and takes 4.2 to 13.4 hours for elimination from blood [5].

Most deaths occur during the first 24 hours after the sting and are secondary to respiratory or cardiovascular failure resulting from autonomic excitation. Cardiac dysfunctions are attributed to catecholamine-induced increases in myocardial metabolism and oxygen demand. It leads to myocardial ischemia-induced myocardial hypoperfusion and to the direct effects of the toxin (leading to myocarditis) [6]. The direct cardiotoxic effect of venom can cause myocarditis by reduction of $\mathrm{Na}^{+}-\mathrm{K}^{+}$-ATPase and by releasing noradrenaline and adrenaline from neurons, ganglia and adrenals, thus increasing myocardial oxygen demand by direct chronotropic and inotropic effect on already compromised myocardial blood supply [7]. The

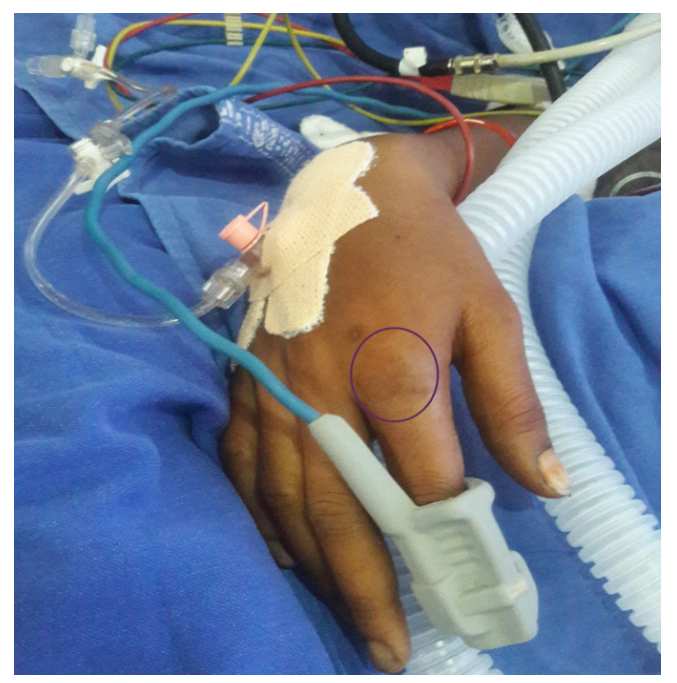

Fig.1: Scorpion bite on right hand.

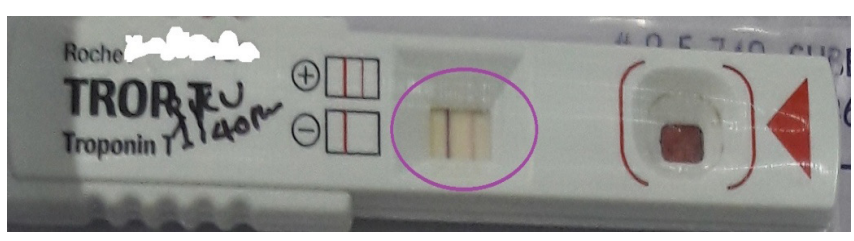

Fig.2: Troponin $T$ test shows positive result.

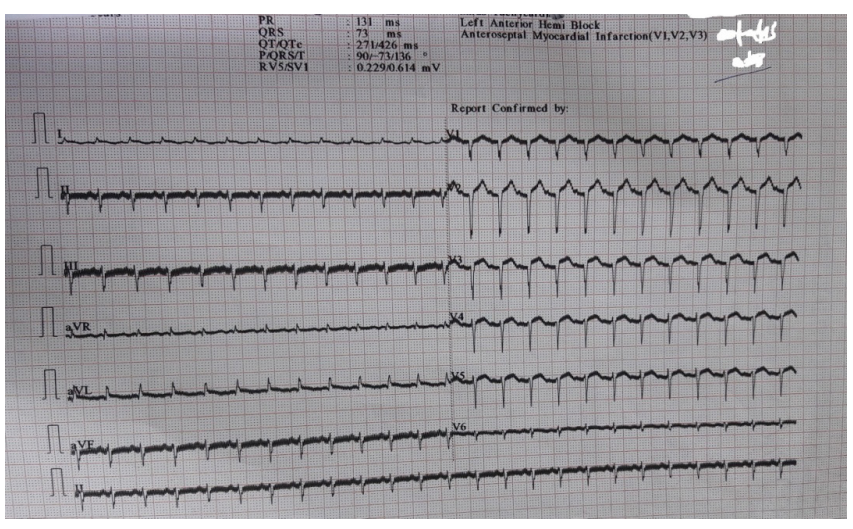

Fig.3: ECG showed sinus tachyacardia, left anterior hemi block, anteroseptal myocardial infarction (V1,V2,V3).

venom is a powerful arrhythmogenic agent. The actions of venom are inhibited by prazosin, atropine, propranolol and phentolamine [8]. The ECG changes are nonspecific but may sometimes suggest myocardial infarction and several types of arrhythmias (both tacky and brady types) have been reported [9]. 
Table 1: The day wise observations and treatment pattern.

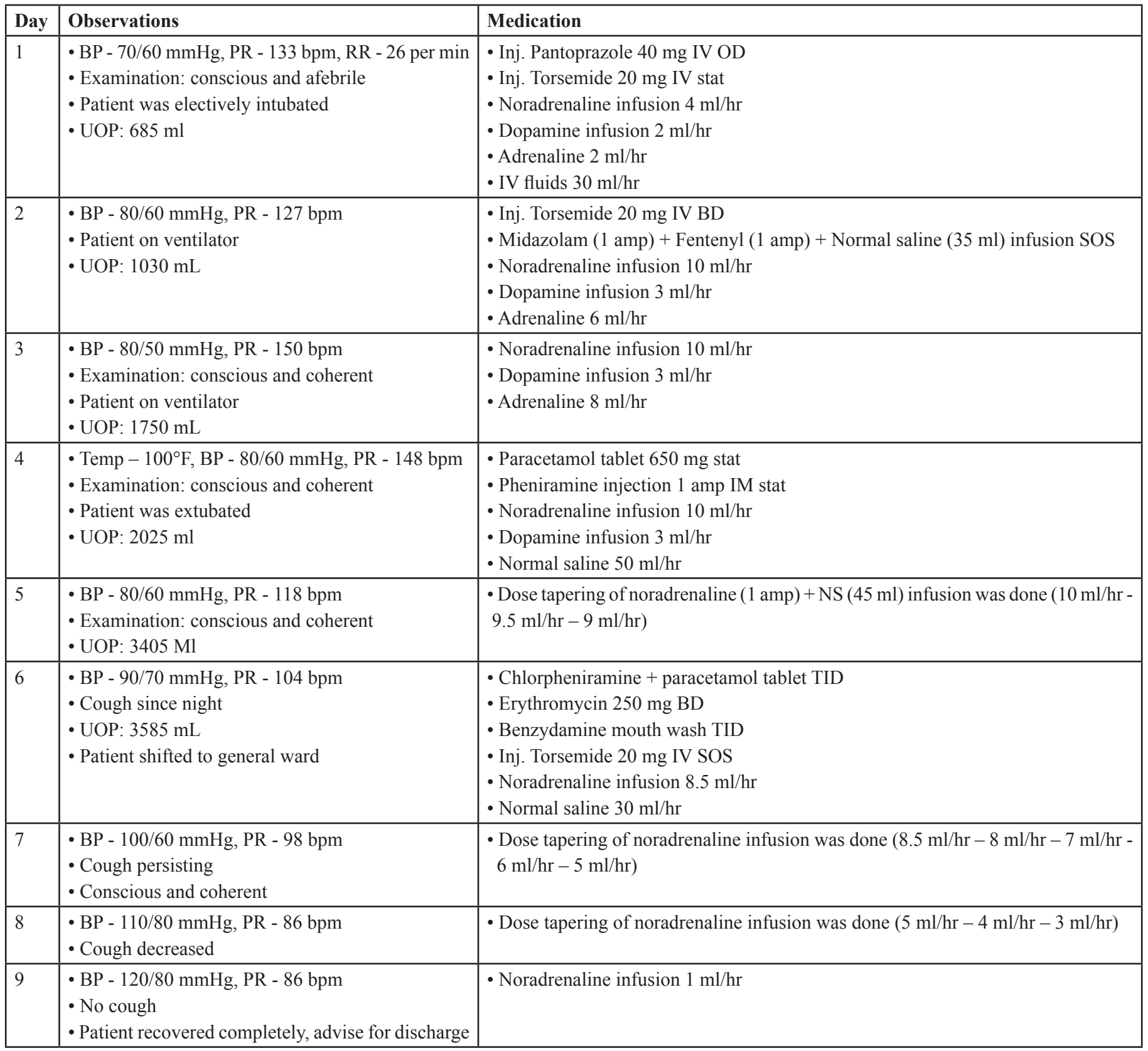

BD: Twice daily, CST: Continue same treatment, IV: Intravenously, IM: Intramuscularly, OD: Once daily, SOS: If needed, STAT: Immediately, TID: Thrice daily, UOP: Urine output.

Myocardial ischemia is not only due to the release of catecholamines but also due to effect of cytokines and/or neuropeptide $\mathrm{Y}$ on coronary vessels. Cardiac damage might be enhanced by the depressive effect of cytokines upon myocardial cells. Hyperglycemia may also contribute to myocardial injury [10]. Valdivia et al. [11] reported a series of 32 children with scorpion bites who developed cardiac complications. Among these, $50 \%$ exhibited myocarditis, $12.5 \%$ had subclinical disease, and $63 \%$ had observable ECG changes. We observed both ECG changes and myocarditis in this case. 


\section{Conclusion}

Myocarditis is an important cause of morbidity and mortality following scorpion sting. High index of suspiction and serial ECG monitoring is required to recognize this complication and institute appropriate management.

Acknowledgement: We would like to express our sincere thanks to Mr. T. Jayapal Reddy Chairman, St. Peter's Institute of Pharmaceutical Sciences, Hanamkonda, Warangal, Telangana State, for providing the facilities.

Contributors: ME: literature review, manuscript writing; BR, MR: critical review of manuscript and case management; SB: manuscript editing and critical inputs into manuscript. ME will act as the guarantor. All authors approved the final version of the manuscript.

Funding: None; Competing interests: None stated.

\section{References}

1. Erfati P. Epidemiology, symptomatology and treatment of buthinae stings. In: Arthpod Venoms. Handbook of Experimental Pharmacology. Bettini S (ed.), Springer Verlag: New York 1978:pp.312-315.

2. Bhadani UK, Tripathi M, Sharma S, Pandey R. Scorpion sting envenomation presenting with pulmonary edema in adults: a report of seven cases from Nepal. Indian J Med Sci. 2006;60:19-23.

3. Bawaskar HS, Bawaskar PH. Indian red scorpion envenoming. Indian J Pediatr. 1998;65:383-391.

4. Chippaux JP, Goyffon M. Epidemiology of scorpionism: a global appraisal. Acta Trop. 2008;107:71-79.

5. Ismail M, Abd-el Salam MA. Are the toxicological effects of scorpion envenomation related to tissue venom concentration? Toxicon. 1988;26:233-256.

6. Satyawali V, Pandey S, Prakash C, Singh Y. Scorpion sting masquerading as myocardial infarction. J Indian Academy of Forensic Medicine. 2014;36:89-91.

7. Rahav G, Weiss AT. Scorpion sting-induced pulmonary edema. Scintigraphic evidence of cardiac dysfunction. Chest. 1990;97:1478-1480.

8. Ismail M, El Asmar MF, Osman OH. Pharmacological studies with scorpion venom; evidence for the presence of histamine. Toxicon. 1975;13:49-56.

9. Garg AK, Pimparkar AB, Abraham PP, Chikhalikar AA. Myocarditis and pulmonary edema following scorpion bite. J Postgrad Med. 1983;29:46-48.

10. Valdivia HH, Kirby MS, Lederer WJ, Coronado R. Scorpion toxins targeted against the sarcoplasmic reticulum $\mathrm{Ca}(2+)$ - release channel of skeletal and cardiac muscle. Proc Natl Acad Sci. 1992;89:12185-12189. 